\title{
Long-Term Consequences of Toxic Epidermal Necrolysis in Children
}

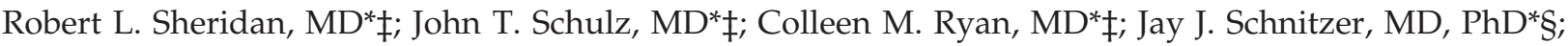 \\ David Lawlor, MD*\|; Daniel N. Driscoll, MD*\|; Matthias B. Donelan, MD*\|; and \\ Ronald G. Tompkins, MD, ScD*ł
}

\begin{abstract}
Objective. Toxic epidermal necrolysis (TEN) is an acute inflammatory systemic condition that involves injury not just to the skin. Historically, it has been associated with a high mortality but few long-term consequences among survivors. With improved survival, long-term consequences may be becoming more apparent. The objective of this study was to define these long-
\end{abstract} term consequences and their frequency.

Methods. From July 1, 1991, to June 30, 2000, 11 children with severe TEN were referred to a regional pediatric burn facility. Wounds were managed with a strategy involving prevention of wound desiccation and superinfection, including the frequent use of biological wound coverings. All children survived and have been followed in the burn clinic. The records of all children were reviewed in detail.

Results. Two boys and 9 girls with an average age of $7.2 \pm 1.8$ years (range: 6 months-15 years) and sloughed surface area of $76 \pm 6 \%$ of the body surface (range: $50 \%-95 \%)$ were admitted to the burn unit for care. Antibiotics ( 3 children), anticonvulsants ( 4 children), nonsteroidals ( 2 children), and viral syndrome or unknown agents ( 2 children) were believed to have triggered the syndrome. Six (55\%) children required intubation for an average of $9.7 \pm 1.8$ days (range: $2-14$ days). Mucosal involvement occurred in $10(91 \%)$ and ocular involvement in $10(91 \%)$. Lengths of stay averaged $19 \pm 3$ days (range: 6-40 days). Overall follow-up averaged $14 \pm 13$ months. Three children had no apparent long-term consequences of the disease and were referred to primary care follow-up after the 2-month burn clinic visit. The remaining children had follow-up averaging $23 \pm 13$ months. The most common long-term morbidity involved eyes ( 3 children [ $27 \%]$ ), nails ( 4 children [36\%]), and variegated skin depigmentation (all children). One child developed vaginal stenosis from mucosal inflammation. No esophageal strictures or recurrent TEN has been diagnosed.

Conclusions. Survival has improved in children with TEN, but long-term sequelae are not infrequent. The most common long-term consequences involve the eyes, the skin, and the nails. Pediatrics 2002;109:74-78;

From the *Shriners Burns Hospital, Boston, Massachusetts; $\ddagger$ Department of Surgery, Division of Burns and Trauma, Massachusetts General Hospital and Harvard Medical School, Boston, Massachusetts; §Department of Pediatric Surgery, Massachusetts General Hospital and Harvard Medical School, Boston, Massachusetts; and \|Department of Surgery, Division of Plastic and Reconstructive Surgery, Massachusetts General Hospital and Harvard Medical School, Boston, Massachusetts.

This work was presented at the Annual Meeting of the American Burn Association; Boston, MA; April 18-21, 2001.

Received for publication Jun 7, 2001; accepted Aug 22, 2001.

Reprint requests to (R.L.S.) Shriners Burns Hospital, 51 Blossom St, Boston, MA 02114. E-mail: sheridan.robert@mgh.harvard.edu

PEDIATRICS (ISSN 0031 4005). Copyright (C) 2002 by the American Academy of Pediatrics.
Stevens-Johnson syndrome, toxic epidermal necrolysis, burns.

ABBREVIATIONS. TEN, toxic epidermal necrolysis; SJS, StevensJohnson syndrome; IVIG, intravenous immunoglobulin preparations.

$\mathrm{T}$ Toxic epidermal necrolysis (TEN) is an acute inflammatory systemic condition that involves injury to the skin, mucous membrane, and sometimes bowel and respiratory epithelium. The syndrome was first clearly described by Lyell in $1956^{1,2}$ and is now believed to represent the most severe form of a disease spectrum beginning with Stevens-Johnson syndrome (SJS). ${ }^{3-5}$ In SJS, mucous membranes are characteristically denuded. Some children with SJS have macular skin lesions as well, usually involving $<30 \%$ of the body surface. In TEN, both skin and mucous membranes are denuded, involvement of $>30 \%$ of the body surface is characteristic, ${ }^{6}$ and mucosal surface involvement may extend into the respiratory and gastrointestinal tracts. $\mathrm{Pa}$ tients with TEN can therefore be considered as having both a cutaneous and a visceral wound. The morbidity and mortality of the condition is as related to involvement of visceral surfaces as it is to that of the cutaneous wound.

Although there are no large exclusively pediatric data sets, patients with TEN are generally reported to have a mortality as high as $70 \%{ }^{7}$; death usually results from sepsis or organ failure. During the past several years, these children have been increasingly referred to burn units, as their needs are similar to those of children with extensive burns: wound care and support of failing organ systems. This shift has resulted in enhanced survival. ${ }^{8-10}$ Although it was believed that there were few long-term sequelae in survivors of TEN, with improved survival, long-term consequences are becoming more apparent.

\section{METHODS}

A review was conducted of all children who were admitted to a regional pediatric burn facility from July 1, 1991, to June 30, 2000. During this time, 11 children with TEN were admitted for care. Inpatient charts were reviewed for acute outcome, and outpatient charts were reviewed for long-term outcome. Permission for the review was granted by the Institutional Human Studies Committee, and the need for consent was waived.

Children were treated in a standard manner. Wounds were managed with a strategy involving prevention of wound desiccation and superinfection. The topical agent of choice was aqueous $0.5 \%$ silver nitrate soaks and dressings changed daily and wetted 
Fig 1. Eye complications were most worrisome. A, Impaired tear production and loss of lashes were seen in $20 \%$ of the children. B, Metaplasia of the conjunctiva was seen in 2 children.
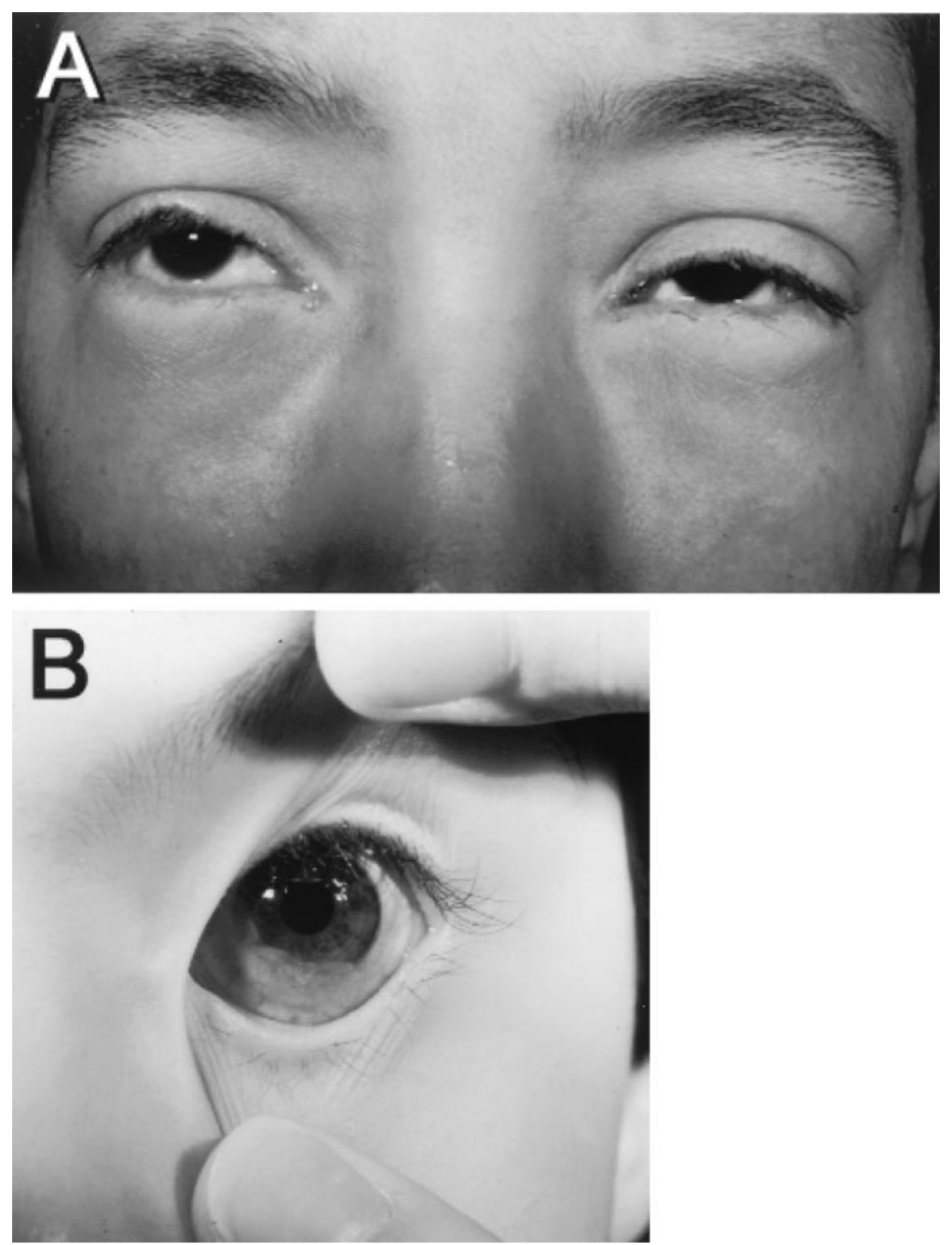

every 2 hours. Shortly after the child's admission, wounds were gently cleansed and loose necrotic epithelium was removed. This was generally done under conscious sedation and was often combined with central venous catheter and feeding tube placement and intubation if required. Dermatologic and ophthalmologic consultations were routinely obtained, and skin biopsy was done. Clean confluent wounds, particularly on anterior torso and extremities, were commonly covered with a biological dressing, typically porcine xenograft (Brennan Medical, St Louis, MO). When the airway was compromised by sloughed mucosa and bleeding or if respiratory failure developed, children were intubated. Vascular access was via the central route. Nutrition was administered by gastric tube feedings. During periods of enteral feeding intolerance, generally associated with sepsis, parenteral nutrition was administered. Antibiotics were used to manage specific foci of infection only, and steroids were not administered. Central venous catheters were changed every week to minimize the occurrence of catheter infections in these children with large open wounds. ${ }^{11,12}$ Pain and anxiety were managed with infusions of morphine sulfate and midazolam, according to our unit routine. ${ }^{13}$ Data are reported as mean \pm standard error of the mean. All children survived and have been followed in the burn clinic.

\section{RESULTS}

Two boys and 9 girls with an average age of $7.2 \pm$ 1.8 years (range: 6 months -15 years) were admitted to the burn unit for care. The surface area of open wound averaged $76 \pm 6 \%$ of the body surface (range: $50 \%-95 \%$ ). Triggering agents for the syndrome were routinely sought via conversations with referring facilities and with parents. Potential triggering agents included antibiotics (3 children: 1 amoxicillin, 2 erythromycin), anticonvulsants (4 children: 1 dilantin, 1 phenobarbital, 2 Tegretol), nonsteroidals (2 children: both ibuprofen), and viral syndrome or unknown agents ( 2 children). This drug list is consistent with other reports.

Endotrachael intubation and mechanical ventilation were required for $6(57 \%)$ of the children for an average of $9.7 \pm 1.8$ days (range: $2-14$ days). Involvement of mucosal surfaces, including the mouth, hypopharynx, esophagus, rectum, and vagina, was common, being documented in 10 children (91\%). Involvement of the conjunctival surfaces was also common and was documented in 10 children (91\%). All children survived, with lengths of stay averaging $19 \pm 3$ (range: $6-40$ ) days.

Infectious complications were common during 
acute care of these children. Five infectious complications were present at admission in 3 children (30\%): 1 bacteremia, 2 pneumonias, and 2 urinary tract infections. Infections that developed in the burn unit included pneumonia in 2 children (18\%), urinary tract infection in $2(18 \%)$, bacteremia in $1(9 \%)$, central line infections in $2(18 \%)$, and candidemia in $2(18 \%)$. Parenteral feeding was required at some time during hospitalization in 5 children (45\%): for transient enteral feeding intolerance secondary to sepsis or presumed gastrointestinal tract involvement in 4 children and for management of pancreatitis in 1 child. All children (100\%) survived after lengths of stay in the burn unit averaging $19 \pm 3$ days (range: 6-40 days).

All children were followed in the burn multidisciplinary clinic. Overall follow-up averaged $14 \pm 13$ months. Three children had no apparent long-term consequences of the disease and were referred to primary care follow-up after the 2-month burn clinic visit. The remaining children had follow-up in the multidisciplinary burn clinic averaging $23 \pm 13$ months.

Ophthalmic morbidity was seen in 3 children $(27 \%)$. These complications included impaired tear production and drainage, aberrant lashes, and dry eye syndrome in all 3 children. Metaplasia of the conjunctiva was noted in 2 children (18\%; Fig 1).

Changes in skin pigmentation were seen in all children. These consisted of scattered areas of depigmented skin that had no relationship to sun exposure (Fig 2). Only 1 child developed any hypertrophic scarring, consistent with the superficial nature of the primary lesion. These mild hypertrophic changes may have been related to protracted supine positioning on open dermis.

Finger and toe nail deformities were also common, although usually minimally symptomatic. These children lost their fingernails toward the end of their hospital stay or in the first few weeks after discharge. The nails that then grew were deformed in shape (Fig 3). These changes were seen in 4 children (36\%) and were usually preceded by swelling and erythema at the nail margin in the acute phase (Fig 3A).

One child (9\%) developed vaginal stenosis from mucosal inflammation. No esophageal strictures or recurrent TEN has been diagnosed.

\section{DISCUSSION}

The pathophysiology of TEN remains unknown but is generally assumed to be an autoimmune phenomenon triggered by drug intake or viral syndrome. The pathophysiology includes a separation of the epidermis at the dermal-epidermal junction of both skin and extracutaneous epithelium and mucous membranes. This results in both a cutaneous and a visceral wound of variable and often unrelated extent. The cutaneous lesions in patients with TEN often begin as a burning or painful eruption on the face, trunk, and proximal upper extremities that then spreads to the entire body. ${ }^{5}$ The appearance of a sheet-like loss of epidermis over large confluent areas is a distinctive characteristic of TEN.${ }^{14}$ Nikolsky's sign, which describes detachment of the full-thick-

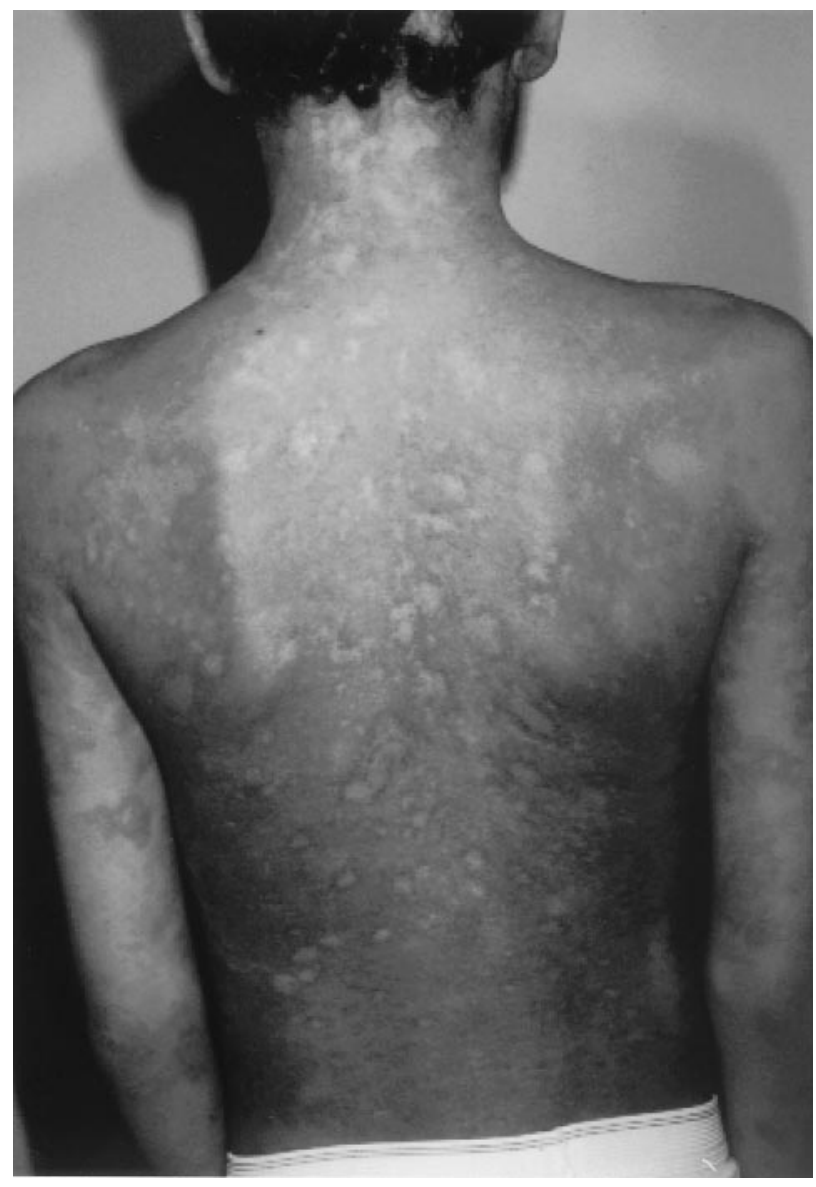

Fig 2. Variegated pigment changes of the skin were very common.

ness epidermis when light pressure is applied with the examining finger, is seen in most children. The cutaneous wound is similar to a second-degree burn and is associated with fluid loss, evaporative heat loss, and pain. Although the diagnosis is readily made on clinical examination, an extensive cutaneous wound with conjunctival and mucous membrane involvement being a unique combination, skin biopsy can be useful in equivocal cases. ${ }^{15-17}$ Biopsy of active lesions will reveal a separation at the dermal-epidermal junction. ${ }^{18}$ Although it is impossible to predict the severity of the disease early in its presentation, children who had a more rapid progression (1 or 2 days) to a large cutaneous wound $(>50 \%)$ and early (first few days) involvement of the eyes and mouth seemed to have longer and more complex hospital stays.

It has been suggested that this disease process is, in large part, immunologically mediated. ${ }^{19}$ The theory is that some form of therapy directed at this cause may be of value, and this contention is supported by small clinical trials with intravenous immunoglobulin preparations (IVIG). ${ }^{20,21}$ One child in this series was treated empirically with IVIG, but at present, data are not sufficient to support this as routine clinical practice. The course of this child's disease was not clearly different from what would have been expected without IVIG treatment. Steroids have been advocated for TEN management in the 
Fig 3. A, Intense inflammation of the nail beds was seen in children who went on to develop nail deformities. B, Nail deformities were seen in $20 \%$ of the children.
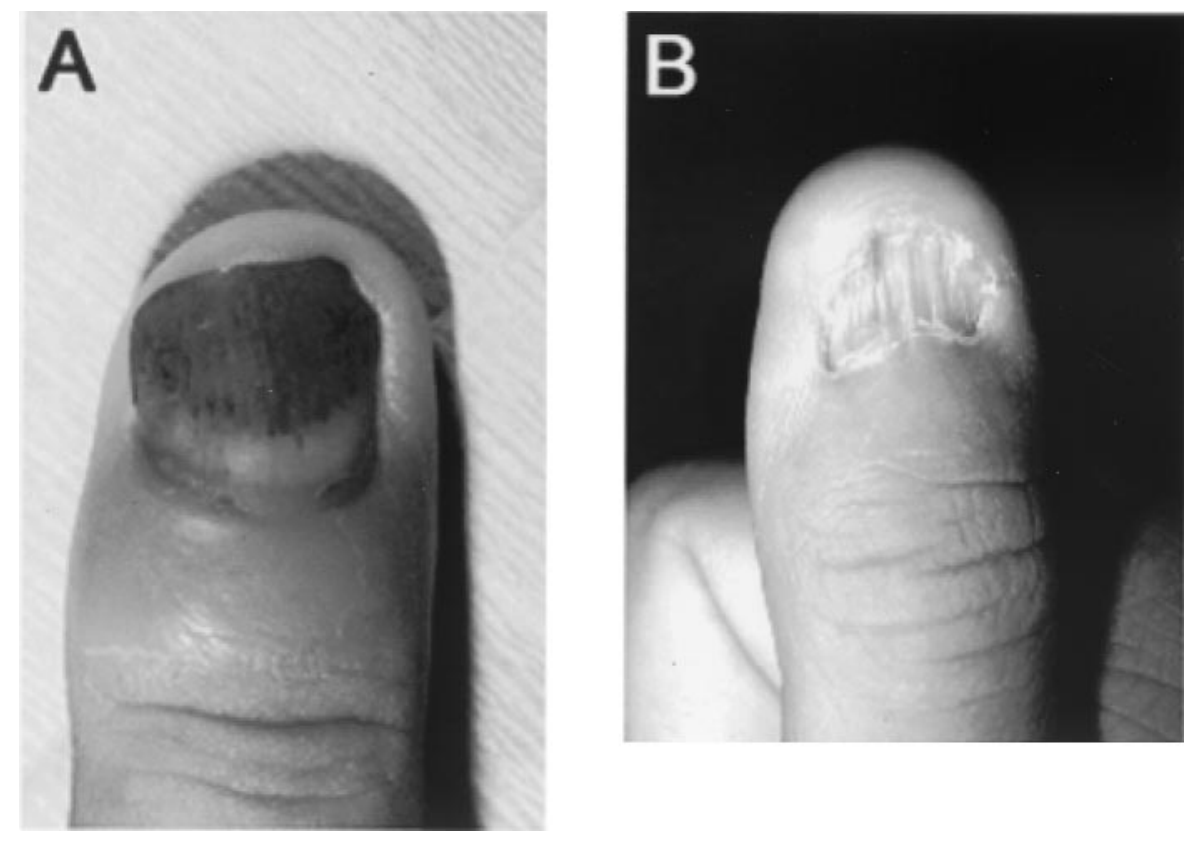

past, but the weight of clinical opinion does not support their use. ${ }^{18,22}$ Plasma exchange also has not proved to be of any benefit. ${ }^{23}$

The visceral wound, resulting from extensive areas of denuded oropharyngeal, gastrointestinal, and tracheobronchial mucosa, varies in extent from minimal to severe, but some degree of mucous membrane and conjunctival involvement is seen in virtually all children. ${ }^{24}$ These wounds seem to be associated with the greatest early mortality and long-term morbidity. Particularly problematic is involvement of the larynx and tracheobronchial tree, which is commonly associated with airway compromise and progressive respiratory failure. ${ }^{25-30}$ Gastrointestinal involvement is seen in the mouth, the esophagus, and even the small bowel and colon, 31,32 with both obstruction and perforation reported as complications. We have not screened for esophageal strictures with radiographs, but no child has demonstrated symptoms suggestive of this problem during the follow-up interval. Vulvovaginal involvement has been reported with variable degrees of stenosis as a result. ${ }^{33}$ However, the most severe long-term sequela may involve the eyes.

Acute ocular complications of TEN include bacterial conjunctivitis, suppurative keratitis, or endophthalmitis. Conjunctival involvement must be recognized early and treated with frequent eye lubrication to prevent desiccation and superinfection of the denuded cornea. The deepithelialized surfaces of the lid and globe will form fibrinous attachments that will become dense if not broken up regularly with a glass rod or heavily lubricated sterile cotton-tipped applicator. The active involvement of an experienced ophthalmologic consultant is important in the care of these children. ${ }^{34}$ Anticipation and management of the long-term ocular complications seen in such children also require experienced ophthalmologic support. Late complications include impaired tear production and drainage, aberrant lashes, and metaplasia of the conjunctiva (Fig 1). ${ }^{35-38}$ These phenomena are inflammatory in nature and will respond to the cautious use of ophthalmic steroid preparations and vigorous lubrication programs. Although there are no data on the efficacy of these measures in reducing long-term eye complications, it seems logical that good lubrication is essential, given that unlubricated globes in children with thermal burns of the eye will predictably develop corneal ulceration and globe rupture. On rare occasion, corneal transplantation may be required, although such has not yet been the case with the children reported here.

All children demonstrated late depigmentation changes of the skin to some degree. These tended to be more pronounced in children with more pigmented uninjured skin. The pigmentation tended to fade with time but did not completely disappear during the follow-up interval and in most children was expected to be permanent. No child required skin grafting. Although it has been reported, ${ }^{39}$ only 1 child in our series developed hypertrophic changes in a localized area of the upper back.

Nail deformities were surprisingly frequent in this group. Although they were generally not painful or associated with significant functional disability, they were universally believed to be significantly unsightly. Those who developed nail deformities usually had obvious inflammation of the nail beds during the acute phase of their illness (Fig 3).

Although prone to infectious complications, most children with TEN can now be expected to survive if treated with a strategy that emphasizes biological wound closure, intensive nutritional support, and early detection and treatment of septic foci. This care can be provided ideally with the resource set unique to burn units. ${ }^{10}$ However, survivors are at risk for a number of significant long-term sequelae and should be followed, ideally in a multidisciplinary burn clinic setting.

\section{ACKNOWLEDGMENT}

This work was supported by the Shriners Hospitals for Children. 


\section{REFERENCES}

1. Lyell A, Dick HM, Alexander JO. Outbreak of toxic epidermal necrolysis associated with staphylococci. Lancet. 1969;1:787-779

2. Lyell A. Toxic epidermal necrolysis. Lancet. 1969;1:1155

3. Lyell A. Toxic epidermal necrolysis (the scalded skin syndrome): a reappraisal. Br J Dermatol. 1979;100:69-86

4. Lyell A. Drug-induced toxic epidermal necrolysis. I. An overview. Clin Dermatol. 1993;11:491-492

5. Roujeau JC, Chosidow O, Saiag P, Guillaume JC. Toxic epidermal necrolysis (Lyell syndrome). J Am Acad Dermatol. 1990;23:1039-1058

6. Marvin JA, Heimbach DM, Engrav LH, Harnar TJ. Improved treatment of the Stevens-Johnson syndrome. Arch Surg. 1984;119:601-605

7. Revuz J, Roujeau JC, Guillaume JC, Penso D, Touraine R. Treatment of toxic epidermal necrolysis. Creteil's experience. Arch Dermatol. 1987;123: 1156-1158

8. Adzick NS, Kim SH, Bondoc CC, Quinby WC, Remensnyder JP. Management of toxic epidermal necrolysis in a pediatric burn center. Am J Dis Child. 1985;139:499-502

9. Heimbach DM, Engrav LH, Marvin JA, Harnar TJ, Grube BJ. Toxic epidermal necrolysis. A step forward in treatment. JAMA. 1987;257: 2171-2175 (published erratum appears in JAMA 1987;258:1894)

10. Sheridan RL, Briggs SE, Remensnyder JP, et al. The burn unit as a resource for the management of acute nonburn conditions in children. J Burn Care Rehabil. 1995;16:62-64

11. Goldstein AM, Weber JM, Sheridan RL. Femoral venous access is safe in burned children: an analysis of 224 catheters. J Pediatr. 1997;130:442-446

12. Sheridan RL, Weber JM, Peterson HF, Tompkins RG. Central venous catheter sepsis with weekly catheter change in paediatric burn patients: an analysis of 221 catheters. Burns. 1995;21:127-129

13. Sheridan RL, Hinson M, Nackel A, et al. Development of a pediatric burn pain and anxiety management program. J Burn Care Rehabil. 1997; 18:455-459

14. Murphy JT, Purdue GF, Hunt JL. Toxic epidermal necrolysis. J Burn Care Rehabil. 1997;18:417-420

15. Arbuthnott JP, Kent J, Lyell A, Gemmel CG. The role of extracellular products of phage group 2 staphylococci in toxic epidermal necrolysis. Contrib Microbiol Immunol. 1973;1:434-440

16. Arbuthnott JP, Kent J, Lyell A, Gemmell CG. Toxic epidermal necrolysis produced by an extracellular product of Staphylococcus aureus. Br J Dermatol. 1971;85:145-149

17. Arbuthnott JP, Gemmell CG, Kent J, Lyell A. Haemolysin and enzyme patterns of coagulase-positive staphylococci isolated from toxic epidermal necrolysis, Ritter's disease and impetigo contagiosa. J Med Microbiol. 1969;2:479-487

18. Guibal F, Roujeau JC, Stern RS. Management of acquired bullous skin diseases. N Engl J Med. 1996;334:864-865

19. Bagot M, Charue D, Heslan M, Wechsler J, Roujeau JC, Revuz J. Impaired antigen presentation in toxic epidermal necrolysis. Arch Dermatol. 1993;129:721-727

20. Viard I, Wehrli P, Bullani R, et al. Inhibition of toxic epidermal necrolysis by blockade of CD95 with human intravenous immunoglobulin. Science. 1998;282:490-493

21. Moudgil A, Porat S, Brunnel P, Jordan SC. Treatment of Stevens-
Johnson syndrome with pooled human intravenous immune globulin. Clin Pediatr. 1995;34:48-51

22. Guibal F, Bastuji-Garin S, Chosidow O, Saiag P, Revuz J, Roujeau JC. Characteristics of toxic epidermal necrolysis in patients undergoing long-term glucocorticoid therapy. Arch Dermatol. 1995;131:669-672

23. Furubacke A, Berlin G, Anderson C, Sjoberg F. Lack of significant treatment effect of plasma exchange in the treatment of drug-induced toxic epidermal necrolysis? Intensive Care Med. 1999;25:1307-1310

24. Roujeau JC. Toxic epidermal necrolysis (Lyell syndrome): more than acute skin failure. Intensive Care Med. 1992;18:4-5

25. Lebargy F, Wolkenstein P, Gisselbrecht M, et al. Pulmonary complications in toxic epidermal necrolysis: a prospective clinical study. Intensive Care Med. 1997;23:1237-1244

26. Wahle D, Beste DJ, Conley SF. Laryngeal involvement in toxic epidermal necrolysis. Otolaryngol Head Neck Surg. 1992;107:796-799

27. McIvor RA, Zaidi J, Peters WJ, Hyland RH. Acute and chronic respiratory complications of toxic epidermal necrolysis. J Burn Care Rehabil. 1996; 17:237-240

28. Wallis C, McClymont W. Toxic epidermal necrolysis with adult respiratory distress syndrome. Anaesthesia. 1995;50:801-803

29. Kamata T, Sakamaki F, Fujita H, et al. Toxic epidermal necrolysis with tracheobronchial and pulmonary complications. Intern Med. 1994;33: 252-255

30. Timsit JF, Mion G, Rouyer N, Le Gulluche Y, Carsin H. Bronchopulmonary distress associated with toxic epidermal necrolysis. Intensive Care Med. 1992;18:42-44

31. Michel P, Joly P, Ducrotte $P$, et al. Ileal involvement in toxic epidermal necrolysis (Lyell syndrome). Dig Dis Sci. 1993;38:1938-1941

32. Carter FM, Mitchell CK. Toxic epidermal necrolysis-an unusual cause of colonic perforation. Report of a case. Dis Colon Rectum 1993;36: 773-777

33. Meneux E, Paniel BJ, Pouget F, Revuz J, Roujeau JC, Wolkenstein P. Vulvovaginal sequelae in toxic epidermal necrolysis. J Reprod Med. 1997;42:153-156

34. Wright P, Collin JR. The ocular complications of erythema multiforme (Stevens Johnson syndrome) and their management. Trans Ophthalmol Soc U K. 1983;103:338-341

35. Power WJ, Ghoraishi M, Merayo-Lloves J, Neves RA, Foster CS. Analysis of the acute ophthalmic manifestations of the erythema multiforme/Stevens-Johnson syndrome/toxic epidermal necrolysis disease spectrum. Ophthalmology. 1995;102:1669-1676

36. Belfort R Jr, de Smet M, Whitcup SM, et al. Ocular complications of Stevens-Johnson syndrome and toxic epidermal necrolysis in patients with AIDS. Cornea. 1991;10:536-538

37. Haus C, Paquet P, Marechal-Courtois C. Long-term corneal involvement following drug-induced toxic epidermal necrolysis (Lyell's disease). Ophthalmologica. 1993;206:115-118

38. Wilkins J, Morrison L, White CR Jr. Oculocutaneous manifestations of the erythema multiforme/Stevens-Johnson syndrome/toxic epidermal necrolysis spectrum. Dermatol Clin. 1992;10:571-582

39. Kavanagh GM, Page P, Hanna MM. Silicone gel treatment of extensive hypertrophic scarring following toxic epidermal necrolysis. Br J Dermatol. $1994 ; 130: 540-541$

\section{HOME MONITORS: KNOCK IT OFF}

“... Physicians who frequently discharge preterm infants with apnea monitors should reevaluate their practice, because no benefit has been demonstrated."

J Pediatr. 2001;139:4A

—Submitted by Alan H. Jobe, MD, PhD 